\title{
الكناية وفوائدها في سورة النساء
}

\author{
Mohammad Idhan, Annisa Maghfirah
}

Institut Agama Islam Negeri Palu, Indonesia

Jl. Diponegoro No. 23, Kec: Palu Barat, Kota Palu, Sulawesi Tengah, 94221, Indonesia Corresponding E-mail: Mohammadidhan63@gmail.com

\begin{abstract}
Penelitian ini bertujuan untuk membahas lebih dalam tentang bentuk-bentuk $i^{\prime} j a z$ yang terdapat pada al-Quran, atau lebih tepatnya yaitu tentang bagaimana bentuk-bentuk kinayah serta maksud yang terkandung dalam lafazh al-Quran yang terdapat di dalam surah an-Nisa. Sehingga diharapkan kita mampu untuk memahami i'jaz atau keindahan makna lafazh yang dijelaskan Allah didalam al-Quran. Metode penulisan yang digunakan dalam menulis penelitian ini adalah metode kualitatif, yang dimaksudkan agar penelitian ini dapat terfokus kepada riset makna bahasa terhadap lafazh yang ada dalam al-Quran itu sendiri. Seperti yang ditemukan dalam salah satu ayat pada surah an-Nisa yaitu kata "tempat yang mulia" yang merupakan makna lain dari surga, dan ini adalah salah satu bentuk lafazh kinayah yang menunjuk kepada bentuk yang disifatinya. Yaitu bahwa surga adalah tempat yang mulia dan diisi oleh orangorang yang mulia pula.
\end{abstract}

Kata kunci: Kinayah, I'jaz, Makna lafazh, An-Nisa

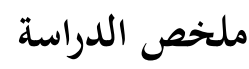

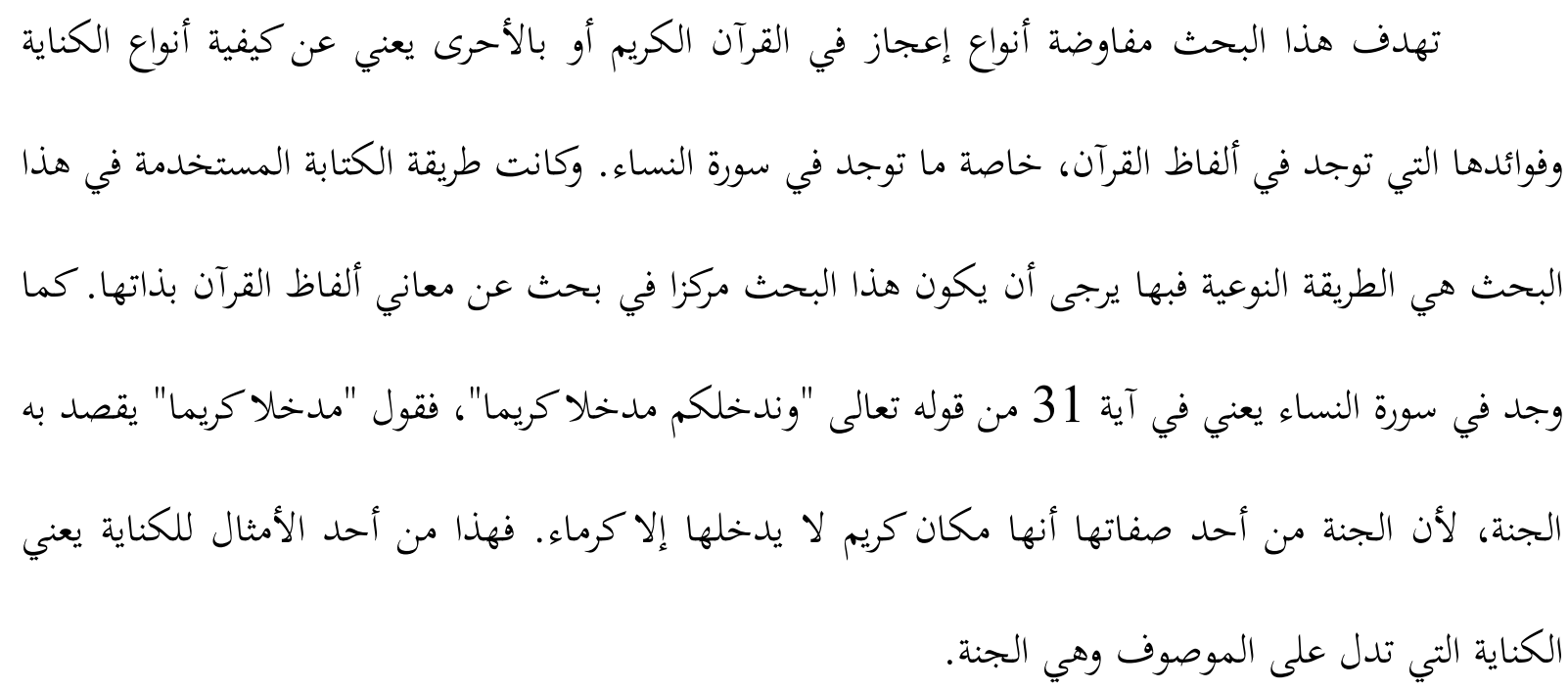

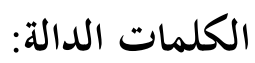

الكناية، الإعجاز، معاني ألفاظ، سورة النساء 


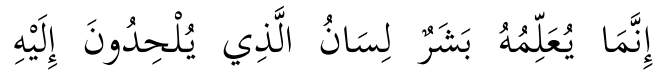

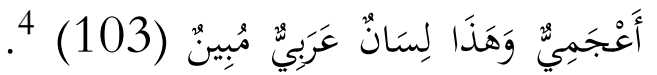
قال الإمام محمد علي الصابوني عن الآية أي لي مالي

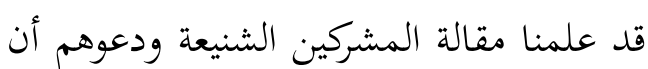
هذا القرآن من تعليم (جبر الرومي)، وقد رد

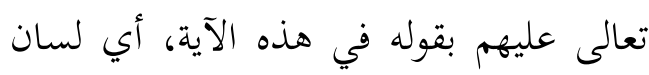
الذي يزعمون أنه علمه وينسبون التعليم أعجمي أن يعلم محمدا هذا الكتاب العربي المبين؟ ومن أين لأعجمي أن يذوق بلاغة هذا الكتاب المعجز في فصاحة وبيانه. 5 وقال

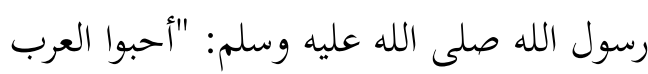
لثلاث، لأني عربي والقرآن عربي، وكلام أهل الجنة عربي (رواه الطبراني).

كما ذكرنا سابقا أن من أراد أن يفهم ويتعمق القرآن يحتاج إلى فهم اللغة العربية، كذالك لمعرفة حسن القرآن لفظا أو معنى يحتاج أيضا إلى فهم العلوم المتعلقة باللغة

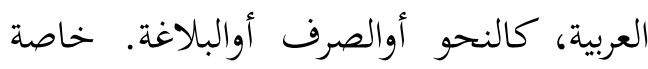
للبلاغة لها دور كبير لمعرفة حسن المعنى الواردة في ألفاظ القرآن الكريم.

$$
\begin{aligned}
& \text { } 403 \text { سورة النحل } \\
& 5 \text { كحمد علي الصابوني، صنوة التغاسير، (بيروت: دار } \\
& \text { القرآن الكريم، 1981م)، } 143
\end{aligned}
$$

اللغة هي ألفاظ يعبر بها كل قوم عن

مقاصدهم. 1 وأما اللغة العربية فهي الكلمات لعات لهات التي يعبر بها العرب عن أغراضهم، ووصلت إلينا من طرق النقل. وحفظها لنا القرآن الكريم والأحاديث الشريفة وما رواه ثقات من منثور العرب ومنظمهم. 2

القرآن هو كلام الله المعجز المنزل

على خاتم الأنبياء والمرسلين بواسطة جبريل عليه السلام المكتوب في المصاحف المنقول إلينا بالتواتر متعبدا بتلاوته المبدوء بسورة الفاتحة المختتم بسورة النساء. كما أنه كتاب أجمع الكتب السماوية وأفضلها ومصدقا لها. لأن قد أودع الله فيه من العقائد والعبادات والفضائل والأحكام والتشريعات والنظرة العلمية إلى الكون ما يجعل حاجة الإنسانية تشتد إليه كلما تحكمت الأهواء وهاجت الغرائر. 3 أنزل الله القرآن باللغة العربية ولو كان المشركون كرهوا بذالك حتى ادعوا بأن محمدا تعلمه يعني القرآن من أعجمي غير فصيح

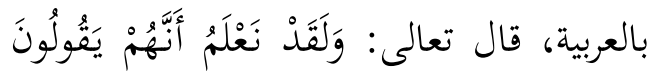

1 مصطفى الغلاييني، جامع الدروس اللغة العربية،

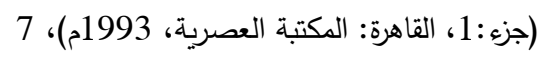

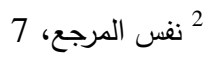
3 محمد علي الصابوني، الطبيان في عاوم القرآن، (مكة المكرمة: مكتبة البشرى، 2011م)، 8 
معينة، يعني أن النظريات تظهر بعد عملية جمع البيانات وتحليلها بالاعتماد على الطريقة الاستقرائية. ونوع هذا البحث هو الدراسة المكتبية، وهي بحث يعتمد على البيانات المتوفرة في الكتب والمراجع العامة، حيث يبدأ الباحثان بالقراءة والاطلاع ثم الكتابة اعتمادا على تلك المصادر والكتب.

\section{نتائج البحث ومناقشتها} لمحة عن الكناية

الكناية في اللّغة، يعني من فعل كنّ

يكنّ كنّا الشّي. 7 وفي كتاب الآخر الكناية هي أن تتكلم بشيء وتريد به غيره، وقد كنيت بكذا عن كذا، وكنوت أيضا كناية فيهما. 8 وأما الكناية في الاصطلاح هي لفظ أريد لازم معناه مع جواز إرادة المعنى الحقيقيّ. 9 وهذا يعني أنّ الكناية لفظ له معنى حقيقيّ ولكن عندما تطلق الكناية لا يراد معناه الحقيقي، بل يراد به

8 عمر بن علوي بن أبي بكر الكاف، البلاغة الدعاني البيان

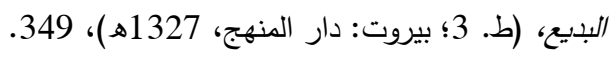
9 عمر بن علوي بن أبي بكر الكاف، البلاغة الدعاني البيان البهان الببيع، 349.
البلاغة لغة هي الوصول والانتهاء إلى الشيء، يقال: "بلغ فلان مراده" إذا انتهى إليه. والبلاغة اصطلاحا هي مطابقة الكلام الفصيح لمقتضى الحال. والبلاغة بمعناها الاصطلاحي لها علوم ثلاثة يعني المعاني والبيان والبديع. ولكن الباحثان يركزان كتابتهما في علم البيان فحسب، خاصة في الكناية. فالبيان لغة الكشف والظهور. وفي الاصطلاح هو أصول وقواعد يعرف بها إيراد المعنى الواحد بطرق متعددة وتراكيب متفاوتة. فلعلم البيان أركان ثلاثة هي التشبيه والمجاز والكناية. فمن أمثلة الكناية قوله "ألقى الجندي سلاحه"، فالمعنى الظاهر من هذه الجملة هو إلقاء السلاح، بينما المعنى الخفي أو الصفة المقصودة هي الاستسلام.

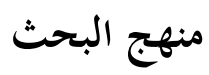
لهذا البحث مدخل تفسيري أي أن الباحثان استندا إلى نتيجة فكرية من علماء وأهل التفسير، حيث أن الباحثان جمعا من البيانات - يعني البيانات الأساسيات والبيانات الثنائيات - التي قام بها للوصول إلى نتيجة

6 عبده عبد العزيز قلقيله، معجم البلاغة العربية نقد ونقض،

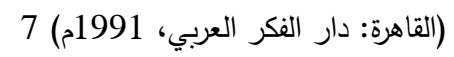

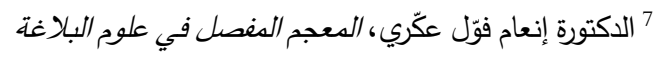

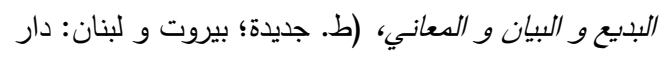
الكتب العلمية، 1317هـ)، 628. 


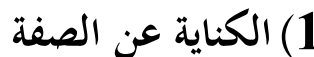

هي الكناية التي تدل على صفة تلازم

المعنى المخفي في الجملة، وهي ضربان:11

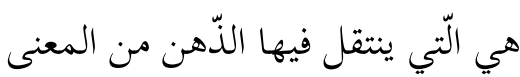

الحقيقيّ للفظ المكنى به إلى المعنى المراد

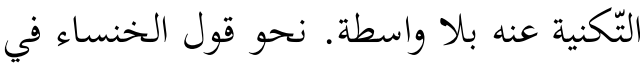

رثاء أخيها صخر:

رفيعَ العمادِ طويلَ النجا ... دِ سادَ عشيرتَهُ

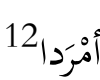

ب. الكناية عن صفة بعيدة

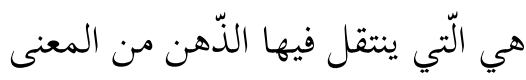

الحقيقيّ إلى المعنى المكنّى عنه بوسائط،

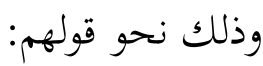

"فلان كثير الّرماد" فإنّه يكنى بها عن صفة هي

الكرم، لكن لا يصل الذّهن إلى هذا المعنى إلاّ

12 عمر بن علوي بن أبي بكر الكاف، البلاغة الدعاني البيان

$$
\text { البديع،359. }
$$

لازم معناه. ومن شروط أن تكون الكناية يعني

الكناية المقصودة لا المجاز هي أن لا

يصحبها قرينة تمنع من إرادة المعنى الحقيقيّ،

وحيئذ تجوز إرادة المعنى من اللّفظ مع لازمه،

إلاّ أنّ إرادة اللاّزم في الكناية أصل والمعنى

الحقيقيّ تبع، وذلك لا يعني أنّ الكناية لا قرينة

لها، بل لا بد من قريينة تفهم أنّ المراد المعنى

اللاّزميّ، لكنّ تلك القرينة لا تمنع أن يراد أيضا

المعنى الحقيقيّ. 10 وقد اتِقق البلغاء على أنّ

الكناية أبلغ من التصريح، وهي تشبيه المجاز،

إلاّ أن المجاز يمنع فيه إرادة المعنى الأصلي،

والكناية لا يمتنع فيها ثبوت المعنى الأصلي.

والكناية تنقسم باعتبار المكنّى عنه إلى

ثلاثة أقسام، أن يكون مكنّى عنه صفة، أو

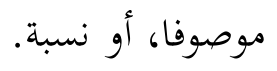


بوسائط، هي أنهّ يلزم من كونه كثير الرّماد أنهّ في هذا البيت يمدح الشّاعر الأبطال الّذين كثير الإيقاد، ويلزم من كونه كثير الطبّخ أنّه يضربون بكلّ سيف أبيض ساطع، والّذين كثير لأكلة، و يلزم من كونه كثير لأكلة أنهّ يطعنون (مجامع الأضغان) أى: الأحقاد. كثير الضّيفان، و يلزم من ذلك الكرم. 13 فنرى فكنى بقوله: (مجامع الأضغان) عن القلب، أنّ بين قولهم (كثير الرّماد) وبين المعنى إذ هو الّذي يوصف بكونه مجامع الأضغان لا المكنّى عنه وهو الكرم، وسائط عدّة يتوصّل غير، وبدلا من أن يقول: (والطّاعنين القلب)

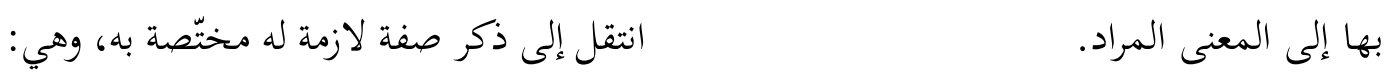
الطّاعنين مجامع الأضغان وأراد ملزومها.

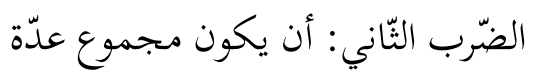

هي التّي يكون المطلوب بها نفس

ألفاظ كناية عن موصوف واحد، وذلك بأن الموصوف. وهذا القسم ضربان. يضمّ لازما آخر حتّى يكون مجموع هذه اللَّوازم مختّصا بموصوف واحد، 15 و ذلك نحو قولهم: "حي مستوي القامة عريض الأظفار" في الكناية عن موصوف واحد هو الانسان، و ليس كلّ وصف منفرد منها يختصّ به، إذ لفظ الضّاربين بكلّ أبيض مخذم - والطّاعنين (حيّ) ليس مختصا بالإنسان، بل يشاركه بها واحدا دالاّ على معنى واحد، وذلك بأن يتّفق في معنى صفة من الصّفات مختصّا بموصوف معين، 14 مثال ذلك: قول الشّاعر: 13 نفس المرجع. 14 البديع، (ط. 3؛ بيروت: دار المنهج، 1327هـ)، 354. 
بقيّة الأحياء، كالفرس والحمار وغيره، الحشرج، بل كنى عن ذلك بقوله مخبرا عن و(مستوى القامة) يشاركه فيها البطريق الثّالثة (في قبّة) أي إنّ محلّ هذه الثّلاثة هو والدّجاج وكلّ من يمشي على رجلين، (قبّة)، وهذه القبّة مضروبة على ابن الحشرج، و وعريض الأظفار) يشاركه فيها الخيل، لكنّ أي إنّها في محلّ مختصّ به لا تتعدّى إلى مجموع هذه الأوصاف لا يشارك الإنسان فيها غيره، لأن الأصل عدم تعدّيها، والشّيء إذا ثبت في مكان مختصّ لشخص، ثبت ذلك

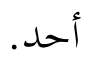
الشّيء لذلك الشّيء لذلك الشّخص.

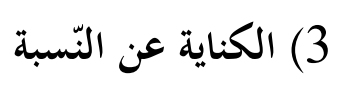
ب. وتنقسم أيضا باعتبار الوسائط أي اللوازم المقصود بالنسبة هي إثبات أمر لأمر والسياق إلى أربعة أقسام: تعريض، تلويح، أو نفيه عنه. والمراد بالكناية عن النّسبة أن

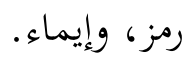
1 يكون اللّفظ مطلوبا به التّكنية عن نسبة بين أمرين. مثال ذلك قول زياد بن الأعجم: لغة: خلاف التصريح، 17 والتعريض اصطلاحا هو خلاف التصريح أي ما أشير به إنّ السّماحة والمروءة والنّدى ... في قبّة ضربت على ابن الحشرج 16 إلى غير المعنى بدلالة السياق، كما تقول: "المسلم من سلم المسلمون من لسانه"، فالمعنى الأصلي انحصار الإسلام فيمن سلم النّاس من يده ولسانه، والمعنى الكنائي اللازم

16 عمر بن علوي بن أبي بكر الكاف، البلاغة المعاني البيان البديع، 364 
لغة: أن تشير إلى قريب منك خفية.

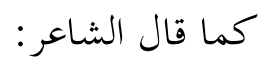

رمزت إلي مخافة من بعلها .... من غير أن

$$
\text { تبدي هناك كلامها }
$$

والرمز في الاصطلاح هو كناية قلت وسائطها

مع خفاء اللزوم نحو قوله: "هو غليظ الكبد"،

كناية عن القسوة، إذ ذلك تتوقف على معرفة

ما كان يعتقده العرب من أن الكبد موضع

الإحساس والتأثر فيلزم من رقته اللين ومن غلظه

$$
\text { القسوة. }
$$

$$
\text { 4) إيماء وإشارة }
$$

وهي كناية قلت وسائطها، مع وضوح

الدلالة، كقول أبي تمام يصف إبله مادحا أبا

سعيد:

21 أحمد الهاشمي، جواهر البلاغة في الدعاني و البيان و البديع، 289. 22 أحمد مصطفى المراغي، علوم البلاغة البيان و المعاني و البديع،306.
المعنى الأصلي انتفاء الإسلام عن المؤذي مطلقا، وهو المعنى المقصود من اللّفظ، ويشير بسياقة إلى نفي الإسلام عن المؤذي الّذي تكلمت عنده. 2) تلويح لغة: أن تشير إلى غيرك من بعد، 19 والتلويح في الاصطلاح كناية كثرت فيها الوسائط بين اللّزم والملزوم، نحو: "أولئك قوم يوقدون نارهم في الوادي" كناية عن بخلهم، فقد إنتقل من الإيقاد في الوادي المنخفض، إلى إخفاء النيران، ومن هذا إلى عدم رغبتهم في اهتداء ضيوفهم إليها، ومن ذا إلى 20 بخلهم. (3 ) رمز 
"إن لم تكن نصلا فغمد نصال"، فهذا من

رديء الكناية، إذ هذا لا يفيد ما قصده من

المعنى، بل ربما جرّ إلى ما يقبح من تحمتها

$$
\text { بالريبة. }
$$

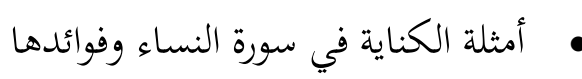

$$
\text { 1. الكناية عن الصفة: }
$$

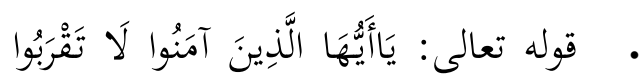

الصَّلَالَة وَأَنْتُمْ سُكَارَى حَتَّى تَعْلَمُوا مَا

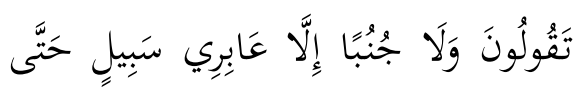

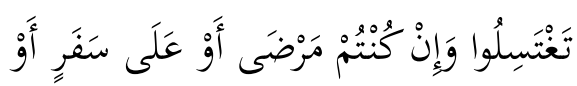

جَاءَ أَحَدُ مِنْكُمْ مِنَ الْغَائِطِ أَوْ لَامَسْتُمُ

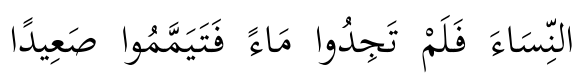

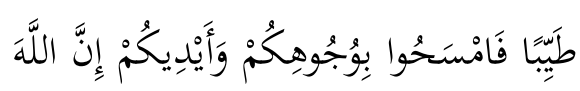

$$
\text { كَانَ عَفُْوًَا غَفُورًا (43) }
$$

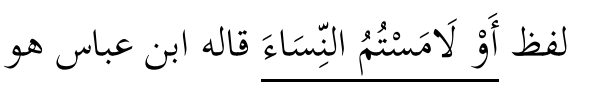

بمعنى الجماع. 24 وهذه الآية تدل على

24 أبو جعر محمد بن جرير بن يزيد بن كثير الطبري،

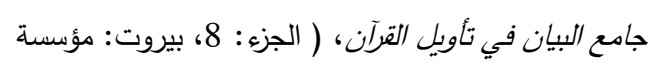
الرسالة، 2000م) 389

$$
\text { يزين أبين فما يزرن سوى كريم ... وحسبك أن }
$$

$$
\text { الفرق بين الكناية والمجاز }
$$

الكناية يشترط فيها أن لا تصحبها

قرينة تمنع من إرادة المعنى الأصلي، والمجاز

هو عكس ذلك، المثال نحو قول رجل: "رأيت

أسدا يتكلم"، لا يمكن أن يكون المراد بالأسد

هنا إلاّ الرّجل الشجاع المهات، وذلك لأنّ

صفة الكلام قرينة منعت إرادة المعنى

الحقيقي.23

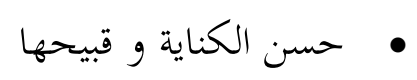

الكناية تكون حسنة إن جمعت بين

الفائدة ولطف الإشارة كما تقدم في الأمثلة،

والكناية تعتبر قبيحة إذا خلت مما ذكر، كقول

$$
\text { الشريف الرضى يرثي امرة: - الم }
$$


وَإِنْ كَانَتْ وَاحِدَةً فَلَهَا النِصْنْ

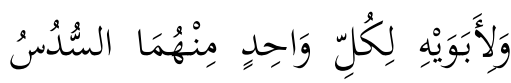

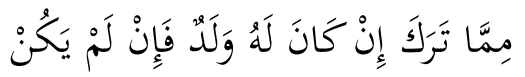

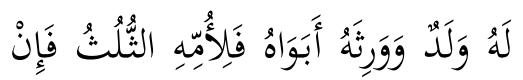

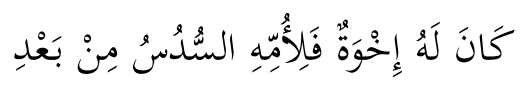

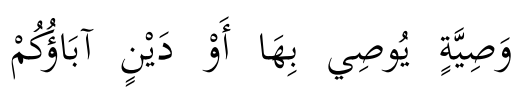

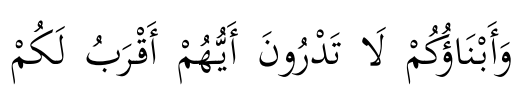
نَفْعًا فَرِيضَةَ مِنَ اللَّهِ إِنَّ اللَّلَ كَانَ

$$
\text { عَلِيمًا حَكِيمًا (11) }
$$

لفظ مِنْكُ حَظِّ الْأْنْيَيْنِ أي أن للابن

من الميراث مثل نصيب البنتين.25 وفائدة هذه الكناية هي الإخبار لتوضيح أقسام الذي يعطى للابن والبنت.

وقول تعالى: وَاللَّاتِي يَأْتِينَ الْفَاحِشَةَ

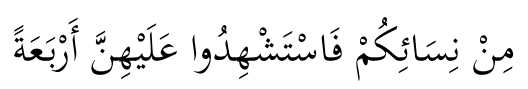
مِنْكُمْ فَإِنْ شَهِدُوا فَأَمِسكُوهُنَّ فِي
صفة يعني صفة قريبة، فائدتها لينقح لفظ

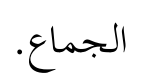

• و وقوله تعالى: وَالَّذِينَ آمَنُوا وَعَمِلُوا

الصَّالِحَاتِ سَنْنْخِلْهُمْ جَنَّاتِ تَجْرِي مِنْ

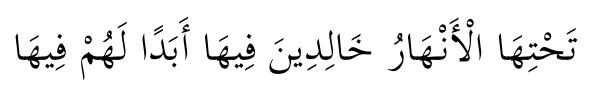

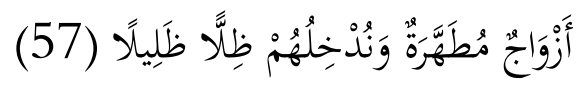

لفظ وَنْدْخِلُهُمْ ظِلَّا ظَلَِيَاً أي بمعنى أن

ذلك المكان الذي وعده الله للمؤمنين لا

تنسخه ظل الشمس مما جعل الجو

ساخنا. وهذه الآية تدل على الكناية عن

صفة، فائدتها لبيان أن الجنة عبارة عن

مكان ومحل بارد بعيد عن سخونة ضوء

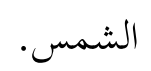

$$
\text { 2. الكناية عن الموصوف: }
$$

• قوله تعالى: يُوصِيكُمُ اللَّهُ فِي أَوَلَادِكْمْ

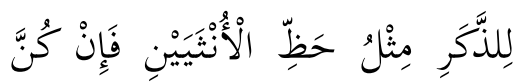

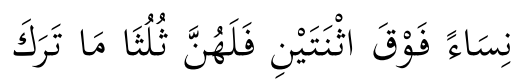

$$
\begin{aligned}
& 25 \text { محمد علي الصابوني، صفوة التفاسير، (الجزء: 1، } \\
& \text { بيروت: دار القرآن الكريم، 1981م)، } 263
\end{aligned}
$$




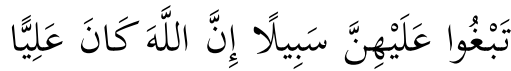

$$
\text { كَبيرًا (34) }
$$

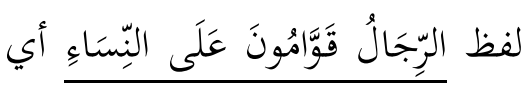

مسلطونة أي قيام سلطانة، كقيام

الولاة على الرباعي، فالمرأة راعية

$$
\text { زوجها. }
$$

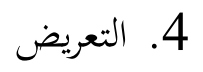

نحو قوله تعالى: إِنَّ اللََّّ لَا يَظْلْمُ

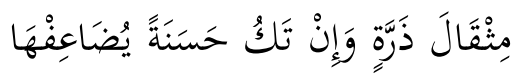

$$
\text { وَيُْوْتِ مِنْ لَحْنْهُ أَجْرًا عَظِيمًا (40) }
$$

فقوله تعالى إِنَّ اللََّّ لَا يَظْلْمُ مِثْعَالَ

ذَِِّة أي أن الله لا يبخس أحدا من

عمله شيئا ولو كان وزن ذرة وهي

الهباء، وذلك على سبيل التمثيل

تنبيها بالقليل على الكثير. وهذه

$$
\text { الآية تدل على صيغة التعريض. }
$$

الْبُيُوتِتِ حَتَّى يَتَتَفَّاهُنَّ الْمَوْتُ أَوْ

يَجْعَلَ اللَّهُ لَهُنَ سَبِيلًا (15)

لفظ الفْحَحِشَةَ في هذه الآية هي من

الكناية عن موصوف يعني الزنا.

وفائدتها هي إخبارا أن الزنا من

أعمال الفاحشة والمنكرات السيئات

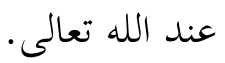

$$
\text { 3. الكناية عن النسبة: }
$$

• ق قوله تعالى: الرِبَجالُ قَوَّامُونَ عَلَى

النِنسّاءٍ بِمَا فَضَّلَ اللَّهُ بَعْضَهُمْ عَلَى

بَعْضٍ وَبِمَا أَنْفَقُوا مِنْ أَمْوَالِهِمْ

فَالصَّالِحَاتُ فَاَنِنَاتُ حَافِظََاتُ لِلْغَيْبِ

بِمَا حَفِظَ اللَّهُ وَاللَّاتِي تَخَافُونَ

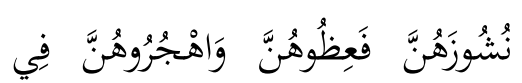

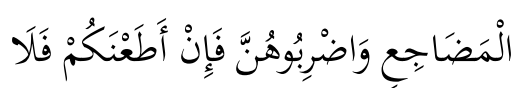

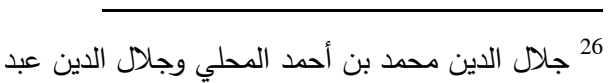

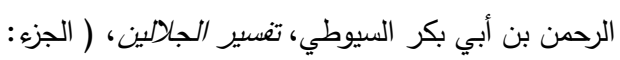

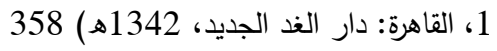


تقليدها. وقد توصلت الدراسة إلى نتيجة

من أنواع الكناية وفوائدها في سورة

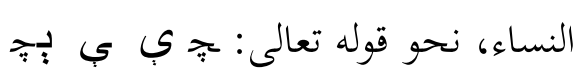

فهذه الكناية عن الصفة بمعنى جامعتم

النساء، فاتخذ الله لفظ "لمس" نقحاعن

"الجماع". و والمثال الآخر نحو قوله

تعالى : إِنَّ اللَّهَ لَا يَظْلْمُ مِثْقَالَ ذَرَّة أي أن

الله لا يبخس أحدا من عمله شيئا ولو

كان وزن ذرة وهي الهباء، وذلك على

سبيل التمثيل تنبيها بالقليل على الكثير.

فهذه الآية تدل على تعريض.

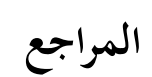

الغلايينى، مصطفى. جامع الدروس اللّغة

العربية، القاهرة: منشورات المكتبة

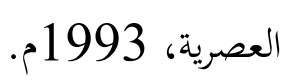

الصابوني، محمد علي. البيان فى علوم القرآن،

مكة المكرمة: مكتبة البشرى،

2011
5. 5لويح

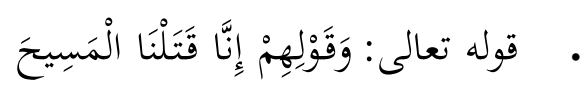

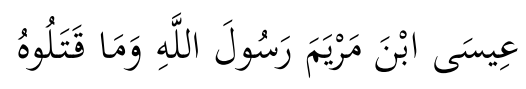

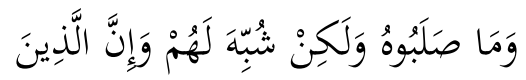

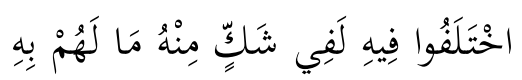

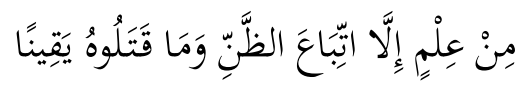

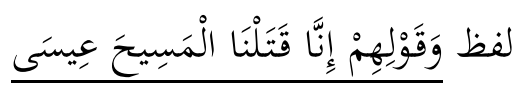

ابْنَ مَرْيَمَ أي قول اليهود "قتنلنا هذا

الذي يزعم أنه رسول الله، وهذا إنما

قالوه على سبيل التهكم والاستهزاء.

والآية أيضا تدل على تلويح.

الخلاصة

أن معجزات القرآن ليست في صدق

محتوياته كما تدل عليها أحداث حقيقية

شوهدت بعيون الإنسان مباشرة فحسب،

بل إن معجزات القرآن كذلك في جمال

صيغته التي لا يمكن لأي إنسان 
Metode Penelitian pendidikan سوكيونو، pendekatan kuantitatif dan R dan D ،kualitatif

$$
\text { 2010 }
$$

إنتان، التحليل النقيضي بين اللّة اندونسيا و

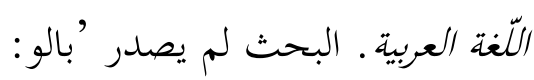

التربية اللّغة العربية كلّية التربية وعلوم

التدريسي في جامعة الحكومية

الإسلامية، 2017 - 2017،
الصابوني، محمد علي، صغوة التغاسير،

الطبعة. 4؛ مجلّد. 1؛ بيروت: دار

$$
\text { القرن الكريم، 1981م؛ }
$$

الجصاص، أحمد الرازي، أبي بكر، أحكام القرآن، 'الطبعة. 1؛ بيروت: دار

الفكر،

القرآن الكريم، سورة النخل.

نعمة، فواد، ملخص قواعد اللّغة العربية،

'الطبعة. 19، جزء. 1؛ بيروت: دار

الثقافة الإسلامية، 1973م؛

قلقيله، عبدة عبد العزيز، معجم البلاغة العربية

نقد و نقص، ' الطبعة. 1؛ القاهرة:

دار الفكر العربي، 1991مُ،

بن على الحرب، عبد العزيز، البلاغة ميسرة، '

الطبعة. 2؛ بيروت و لبنان: دار ابن

حزم، 2011م' - 2011

بن أبي بكر الكاف، عمر بن علوي، البلاغة

المعاني-البيان-البديع، 'الطبعة. 3؛ بكرين

لبنان و بيروت و فاكس: دارالمنحج،

. 2006

المراغي، أحمد مصطفى، تغسير المراغي،

'الطبعة. 1، جزء. 4؛ كيرة و مصر:

مصطفى البابي الحلبي، 1946م؛. 